\title{
Solidification of a Steel Billet in the Mold of a Synchronized Rotary Type Continuous Caster*
}

\author{
By Hideyo KODAMA, ,* Eisuke NIYAMA,** Minoru HORIGUCHI,** \\ Tomoaki KIMURA ${ }^{* * *}$ and Munehiro ENDO***
}

\begin{abstract}
Synopsis
A high speed continuous billet caster where casting speed matches the rolling speed has been developed. The mold of the caster consists of a copper wheel with a groove and an endless belt, both strongly cooled by water. There is almost no friction between the mold and a cast billet because of the mold moving simultaneously with a billet. In the course of development two studies were performed to establish the optimum casting and operating conditions. The first was to study the effects of casting conditions on the shell thickness in the mold. The second was on the heat transfer characteristics of the rotating wheel. The results are summarized as follows:
\end{abstract}

(1) The solid shell thickness of the belt side was smaller than that of the wheel side when the molten steel with large superheat was poured.

(2) Water modeling experiment revealed that flow with high velocity went downward along the belt side, while there was upward flow with low velocity along the wheel side.

(3) The allowable superheat was estimated to be $50^{\circ} \mathrm{C}$ by the casting experiments and computer calculation taking account of fluid flow.

(4) Good contact between a cast billet and the wheel was obtained by smooth nozzle stream, tension casting where the pinch rollers were driven at a slightly higher rate than the wheel and appropriate guide roller configuration.

(5) The solidification rate constant was $27 \mathrm{~mm} / \mathrm{min}^{1 / 2}$, which was somewhat larger than that of an average conventional caster.

Based upon these results the belt wheel type continuous caster was put into practical use.

\section{Introduction}

The conventional continuous caster can not match the productivity of rolling mills because of its low casting speed. Therefore generally two or three casters need to be installed to catch up with rolling mill speed. In such cases billets from each caster need to be cut, separated or merged, and moreover need to be reheated for rolling. Then if casting speed is high enough to match rolling speed, not only the number of casters can be minimized, but also direct rolling where casting and rolling are tightly connected can be put into practical use. Further less external heating due to high casting speed may lead to energy saving. From this background we started the program of development and practical application of a continuous caster whose casting speed is more than two times higher than that of the conventional caster.

The conventional continuous caster where cast billets are withdrawn from an oscillated mold is unacceptable for high speed casting due to friction between a mold and a solidified shell. On the other hand in a synchronized rotary type continuous caster a mold moves simultaneously with a solidified shell. This type is acceptable for high speed casting. Among various kinds of rotary casters ${ }^{1)}$ we selected a belt wheel caster because of high speed casting feasibility and structural simplicity.

With this type of a continuous caster a solidified shell of an arc shape with large curvature is formed in the synchronized rotating mold, and is straightened just after leaving the mold. Thus in the course of development the effects of nozzle stream on the solidification of shell and the casting conditions necessary for smooth straightening had to be studied.

For this purpose the factors affecting solidification were studied by casting experiments with the prototype rotary caster, a water modeling test and calculation of solidification. Moreover during the test operation of the first commercial caster, the effects of casting conditions on the shell growth and mold heat transfer were also examined.

From these results the synchronized rotary caster for steel was put into practical use for the first time in the world. This paper presents the main features of the rotary caster and solidification of a cast billet.

\section{Structure of the Synchronized Rotary Type Continuous Caster6,7)}

Tables 1 and 2 show main specifications of the prototype and commercial rotary type continuous casters, respectively. The general plan and the structure of the casting machine are shown in Figs. 1 and 2. The first commercial caster was selected as the promotional project of new machine development sponsored by Mechanical Social Systems Foundation and was installed at Kameido Works of Daisan Steel Co. in March 1979. The outline of the commercial caster is described in the following.

The mold consists of a $3 \mathrm{~m}$ diameter casting wheel and a steel belt. Liquid steel held in a tundish is vertically poured. The solidified shell is formed in the mold, straightened near the bottom of the wheel and horizontally withdrawn. After solidification completes through a spray zone, an air cooling zone and a soaking zone, a cast billet is direct-rolled by a vertical mill and a horizontal mill and then cut into certain length.

Main features are:

1) Nozzle: A vertical open-type, made of fused silica.

\footnotetext{
* Originally published in Tetsu-to-Hagané, 67 (1981), No. 8, Special Issue on Continuous Casting of Steel, 1394, in Japanese. English version received April 2, 1982 . (C) 1983 ISIJ

** Katsuta Office, Hitachi Research Laboratory, Hitachi Ltd., Horiguchi, Katsuta 312.

*** Hitachi Works, Hitachi Ltd., Saiwai-cho, Hitachi 317.
} 
Table 1. Specifications of the prototype casting machine.

\begin{tabular}{l|l} 
Casting section & $100 \times 120 / 140 \mathrm{~mm}$ \\
Cast metal & Plain carbon steel \\
Casting speed & Max. $10 \mathrm{~m} / \mathrm{min}$ \\
Wheel & $\phi 2440(\mathrm{AgCuB})$ \\
Belt & $2.6 \mathrm{t} \times 250 \mathrm{~B}(\mathrm{SPCG})$ \\
\hline
\end{tabular}

Table 2. Main features of the commercial casting machine.

\begin{tabular}{l|l} 
Casting section & $130 \times 160 / 190 \mathrm{~mm}$ \\
Cast metal & Plain carbon steel, Si-Mn steel \\
Casting speed & 3 to $6 \mathrm{~m} / \mathrm{min}$ \\
Wheel & $\phi 3000(\mathrm{AgCuB})$ \\
Belt & $2.6 \mathrm{t} \times 280 \mathrm{~B}(\mathrm{SPCC})$ \\
Production & Max. $60 \mathrm{t} / \mathrm{h}$
\end{tabular}

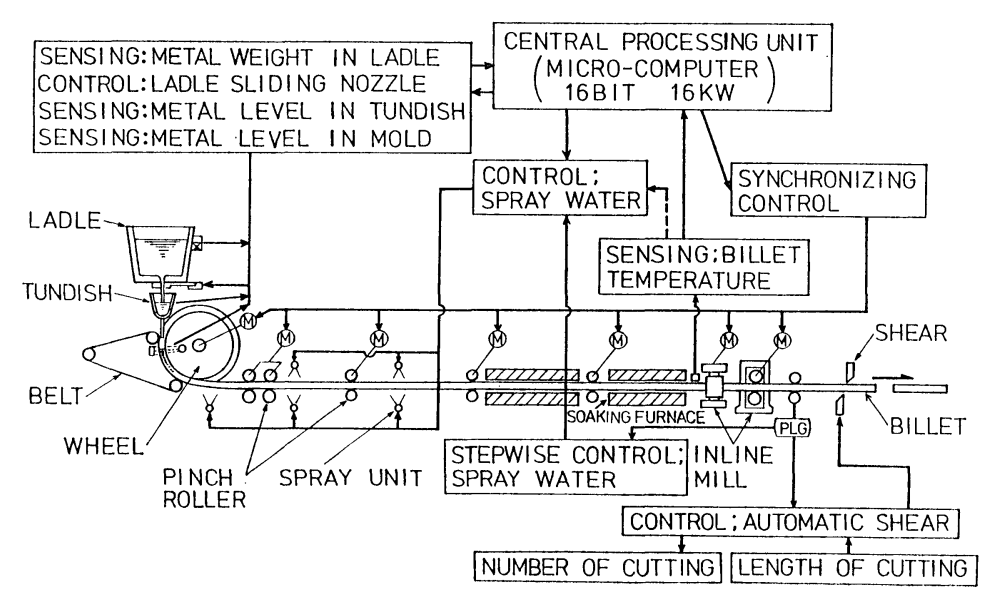

Fig. 1.

General plan and control system of the commercial continuous casting machine.
Fig. 2.

Structure of the commercial continuous casting machine.

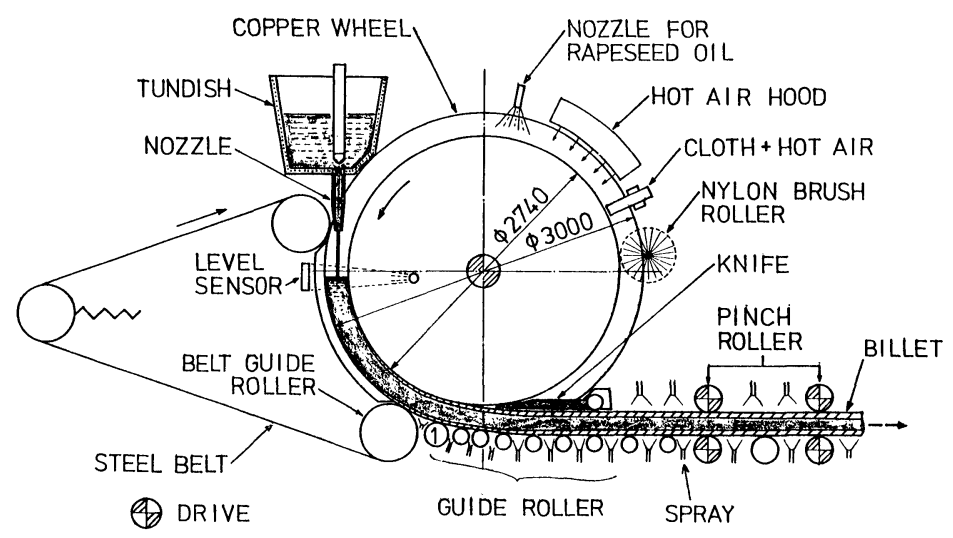

unbending radius and higher casting speed than those of conventional casters. In order to prevent crack formation, therefore, straightening is performed not at one point but over a distance of about $1 \mathrm{~m}$ to keep the strain rate almost constant. As shown in Fig. 2, the configuration of a knife and guide rollers is designed on this consideration.

6) Direct rolling: After complete solidification and soaking a cast billet with the section size of $130 \mathrm{~mm} \times 160 \mathrm{~mm} / 190 \mathrm{~mm}$ is rough-rolled first by a vertical mill, and then by a horizontal mill into a billet usually with the size of $130 \mathrm{~mm} \times 130 \mathrm{~mm}$. Due to high speed casting reheating of cast billets in a soaking furnace is not required.

7) Control: As shown in Fig. 1 the whole system of the caster is automatically controlled. The nozzle stopper is used only at the start and the end of casting operation. The molten steel level in the mold is monitored by a gamma-ray level gauge and is kept constant by adjusting the speed of the rotating wheel. The speeds of the pinch 
rollers and the rolling mills are synchronized with the wheel.

\section{Effects of Casting Temperature on the Solid Shell Thickness}

\section{Casting Experiments with the Prototype Machine}

In the synchronized rotary type continuous caster a cast billet is straightened when the solid shell thickness is small. If there is a significant difference in the shell thickness along the casting direction, straightening may not be performed smoothly. Therefore it is important and beneficial to promote uniform solidification.

In order to examine the effects of casting temperature on the shell thickness, casting experiments with the prototype machine were carried out. Table 3 shows the casting conditions. The casting temperature was a measured value in the tundish. The liquidus temperature was calculated from the alloy composition.

Figure 3 shows the solid shell thickness of the longitudinal section of billets measured by a bleeding test during casting. Under condition $B$ the shell thickness is almost equal both along the belt side and along the wheel side. On the other hand under condition A where the superheat was larger than that of B, although the shell thickness gradually increased with time and became almost the same as that of $\mathrm{B}$, the belt side shell thickness was relatively small especially within $600 \mathrm{~mm}$ distance from meniscus.

The superheat and also molten steel flow seem to affect the solid shell thickness.

Table 3. Gasting conditions.

\begin{tabular}{l|c|c}
\hline \multicolumn{1}{c|}{ Condition } & A & B \\
\hline Cast metal & $0.2 \% \mathrm{C}$ steel & $0.2 \% \mathrm{G}$ steel \\
Casting temp. & $1590^{\circ} \mathrm{C}$ & $1562^{\circ} \mathrm{C}$ \\
Liquidus temp. & $1510^{\circ} \mathrm{C}$ & $1510^{\circ} \mathrm{C}$ \\
Superheat & $80^{\circ} \mathrm{C}$ & $52^{\circ} \mathrm{C}$ \\
Casting speed & $4.7 \mathrm{~m} / \mathrm{min}$ & $5.0 \mathrm{~m} / \mathrm{min}$ \\
\hline
\end{tabular}

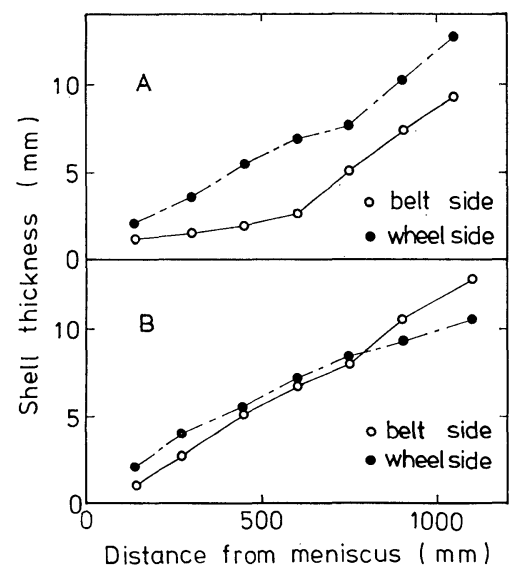

Fig. 3. Solid shell thickness measured by a bleeding test.

\section{Water Modeling Test}

As described in Section III. 1, solidification along the belt side was affected by superheat. The position where the shell thickness was especially small was supposed to be the region where the motion of fluid flow induced by the nozzle stream was dominant. Thus the water modeling test was carried out to observe the fluid flow pattern in the mold.

\section{Experimental Procedure}

The $2 \mathrm{~m}$ long mold of the same radius as the prototype machine shown in Table 1 , the pouring nozzle of the actual machine size and the tundish were made of transparent polymer. Figure 4 shows the outline of the experimental apparatus. The exit diameter of the nozzle was $18 \mathrm{~mm}$ and the distance between the nozzle end and the meniscus was set to $350 \mathrm{~mm}$. The flow rate was $66 \mathrm{l} / \mathrm{min}$, corresponding to the casting speed of $5 \mathrm{~m} / \mathrm{min}$. The tracers of about $1 \mathrm{~mm}$ dia. polystyrene powder (specific weight 1.03) were added to the water flow at the nozzle entrance in order to facilitate observation of the flow pattern in the mold and also calculation of the flow velocity by photographing the trajectories of the tracers. Although some air trappment occurred when the nozzle stream reached the meniscus, the trajectories were almost not affected by the trapped air.

\section{Results and Discussion}

The fluid flow patterns observed from the side of the mold, the belt side and the wheel side are shown in Fig. 5. Along the belt the flow was mainly downward within the distance of $550 \mathrm{~mm}$ from the meniscus. On the other hand, the flow went upward along the wheel. This upward flow was the branched flow of the downward flow along the belt. Details of the belt side flow were; there was almost no particular direction of flow along $150 \mathrm{~mm}$ distance from the meniscus. Afterwards the fluid from the nozzle spread fanwise and passed rapidly $430 \mathrm{~mm}$ distance along the belt, then the flow speed gradually decreased and the flow became uniform. The part of the fluid flowing along the middle of the belt de-

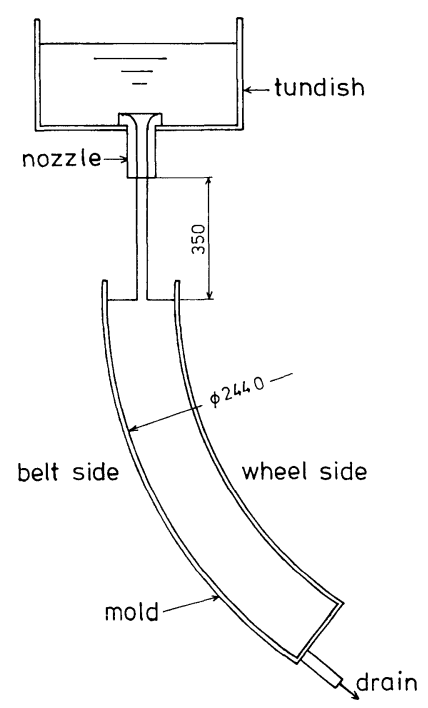

Fig. 4. Experimental apparatus for water modeling. 

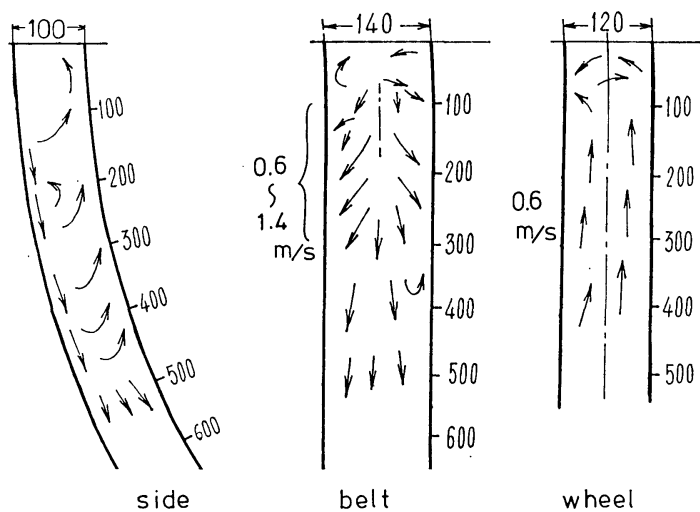

Fig. 5. An example of flow patterns in the mold.

celerated near the mold corner, and the part of this fluid branched upwards.

In Fig. 5 the flow velocities calculated from the trajectories of tracers are also shown. The downward flow after colliding against the belt was from 0.6 to $1.4 \mathrm{~m} / \mathrm{s}$ on the average. This was substantially lower compared to $5.0 \mathrm{~m} / \mathrm{s}$, the mean speed of the nozzle stream just above the meniscus. The momentum of nozzle stream seems to decay in the mold. The upward flow velocity along the wheel side was $0.6 \mathrm{~m} / \mathrm{s}$, slower than the belt side downward flow. The region where the downward velocity along the belt side is high is almost identical to the position of small shell thickness.

It is deduced that molten steel stream will retard the growth of a solid shell, if superheat is large. Then solidification calculation including the effects of superheat and fluid flow was carried out and compared with the results of the casting experiments.

\section{Calculation of Solidification}

\section{Calculation Procedure}

We consider one-dimensional solidification of pure metal for simplicity. The assumptions are in the following.

(1) The change of the velocity of fluid flow is treated by changing the heat transfer coefficient between liquid metal and a solid shell.

(2) Thermal properties of liquid and a solid shell are equal and independent of temperature.

The basic heat conduction equation, boundary conditions and initial condition are written as follows ${ }^{4)}$ :

$$
\begin{array}{ll}
\frac{\partial T}{\partial t}=\alpha \frac{\partial^{2} T}{\partial y^{2}} & \text { for } 0 \leq y \leq Y \ldots \ldots \ldots \ldots \\
K \frac{\partial T}{\partial y}=h_{c}\left(T-T_{0}\right) & \text { for } y=0 \ldots \ldots \ldots \ldots \ldots \ldots \ldots \ldots \\
T=T_{s} & \text { for } y=Y \ldots \ldots \ldots \ldots \ldots \ldots \\
\rho L \frac{d Y}{d t}=K \frac{\partial T}{\partial y}-h_{i}\left(T_{b}-T_{s}\right) \text { for } y=Y \\
Y=0 \quad \text { for } t=0 \ldots \ldots \ldots \ldots \ldots
\end{array}
$$

where, $T$ : temperature $\left({ }^{\circ} \mathrm{G}\right)$

$t:$ time (s)

$\kappa:$ thermal conductivity $\left(\mathrm{cal} / \mathrm{cm} \cdot \mathrm{s} \cdot{ }^{\circ} \mathrm{C}\right)$

$\mathcal{T}_{0}$ : cooling water temperature $\left({ }^{\circ} \mathrm{C}\right)$
$T_{s}$ : melting temperature $\left({ }^{\circ} \mathrm{C}\right)$

$\rho:$ density $\left(\mathrm{g} / \mathrm{cm}^{3}\right)$

$L:$ latent heat of fusion $(\mathrm{cal} / \mathrm{g})$

$T_{b}$ : liquid metal temperature $\left({ }^{\circ} \mathrm{G}\right)$

$C$ : specific heat $\left(\mathrm{cal} / \mathrm{g} \cdot{ }^{\circ} \mathrm{C}\right.$ )

$\alpha$ : thermal diffusivity $\left(\mathrm{cm}^{2} / \mathrm{s}\right)$

$Y:$ solid shell thickness $(\mathrm{cm})$

$y$ : distance $(\mathrm{cm})$

$h_{c}$ : heat transfer coefficient between a solid shell and cooling water $\left(\mathrm{cal} / \mathrm{cm}^{2} \cdot \mathrm{s} \cdot{ }^{\circ} \mathrm{C}\right)$

$h_{i}$ : heat transfer coefficient between liquid metal and a solid shell $\left(\mathrm{cal} / \mathrm{cm}^{2} \cdot \mathrm{s} \cdot{ }^{\circ} \mathrm{C}\right)$.

We apply the collocation method ${ }^{3)}$ to the combination of Eqs. (1) to (5). The temperature distribution in a solid shell is assumed to have the form of a quadratic equation (6).

$$
T=A_{0}+A_{1}(Y-y)+A_{2}(Y-y)^{2}
$$

After manipulating, $A_{1}$ and $A_{2}$ are expressed in the following (see Appendix).

$$
\begin{aligned}
& 2 m A_{2}+A_{1}^{2}+\theta_{b} A_{1}=0 \ldots \ldots \ldots \ldots \ldots \ldots \ldots \ldots \ldots \ldots \ldots \ldots \ldots \ldots \ldots \ldots \\
& K\left(-A_{1}-2 Y A_{2}\right)=h_{c}\left\{\left(\mathcal{T}_{s}-\mathcal{T}_{0}\right)+A_{1} Y+A_{2} Y^{2}\right\}
\end{aligned}
$$

From Eqs. (7) and (8), $A_{1}$ is written in the form of

$$
A_{1}=\frac{\left(a_{1}-a_{2} \theta_{b}\right)-\sqrt{\left(a_{1}-a_{2} \theta_{b}\right)^{2}+4 a_{2} h_{c}\left(T_{s}-T_{0}\right)}}{2 a_{2}}
$$

where, $m=L / C$

$$
\begin{aligned}
& \theta_{b}=h_{i}\left(\mathcal{T}_{b}-\mathcal{T}_{s}\right) / K \\
& a_{1}=K+h_{c} Y \\
& a_{2}=\frac{K Y}{m}+\frac{h_{c} Y^{2}}{2 m}
\end{aligned}
$$

Equations (4) and (9) lead to Eq. (10), expressing the shell thickness $Y$ with time $t$. Therefore, by numerically integrating Eq. (10), $Y$ can be obtained in terms of $t$.

$$
\frac{d Y}{d t}=\frac{1}{\rho L}\left\{-K A_{1}-h_{i}\left(\mathcal{T}_{b}-T_{s}\right)\right\}
$$

In Eq. (10) if the velocity of fluid flow is unchanged, $h_{i}$ is constant. With any velocity change in fluid flow, $h_{i}$ varies. Based on the above algorism a computer program was prepared to calculate the shell solidification.

The heat transfer coefficient between liquid and a solid shell, $h_{i}$, was estimated in the following. Solidification in the mold is, from a heat transfer viewpoint, regarded that molten steel goes through the region surrounded by a solid shell. Then by treating the interface between a solid shell and molten steel as a tube wall, $h_{i}$ was calculated from non-dimensional correlation ${ }^{5)} \quad \mathcal{N}_{u}=3.27+0.019 P_{e}^{0.8}$ where $\mathcal{N}_{u}$ is Nusselt Number, $P_{e}$ being Peclet Number, expressing heat transfer from turbulent flow to a tube wall with a square cross section and a constant wall temperature. Figure 6 shows $h_{i} v s$. flow velocity of molten steel derived from this non-dimensional correlation.

Table 4 shows the flow velocity obtained from the 
water modeling test, the values of $h_{i}$ from Fig. 6 and the application time of each $h_{i}$ value. The flow pattern was divided into 4 zones along the belt side and 2 zones along the wheel side, respectively. The flow velocity in the uniform flow was assumed to be $2 \mathrm{~cm} / \mathrm{s}$. The casting speed was $5 \mathrm{~m} / \mathrm{min}$. The superheat of molten steel, $\Delta T$, was varied from 50 to $90^{\circ} \mathrm{C}$. Other numerical values used for the calculation were;

$$
\begin{array}{rlrl}
T_{s} & =1500{ }^{\circ} \mathrm{C} & K & =0.07 \mathrm{cal} / \mathrm{cm} \cdot \mathrm{s} \cdot{ }^{\circ} \mathrm{C} \\
C & =0.16 \mathrm{cal} / \mathrm{g} \cdot{ }^{\circ} \mathrm{G} & \rho & =7.0 \mathrm{~g} / \mathrm{cm}^{3} \\
L & =65 \mathrm{cal} / \mathrm{g} & T_{0}=20^{\circ} \mathrm{C} \\
h_{c} & =0.025 \mathrm{cal} / \mathrm{cm}^{2} \cdot \mathrm{s} \cdot{ }^{\circ} \mathrm{C} \text { (the belt side) } \\
h_{c} & =0.03 \mathrm{cal} / \mathrm{cm}^{2} \cdot \mathrm{s} \cdot{ }^{\circ} \mathrm{C} \text { (the wheel side) }
\end{array}
$$

\section{Results of Calculation}

Figure 7 shows the calculated shell thickness. Along the belt side the shell thickness is relatively small in the position where the nozzle stream strongly hits the belt. As the superheat is larger, the shell thickness is smaller. Afterwards the shell grows smoothly.

On the contrary along the wheel side with a lower flow velocity than the belt side, the shell thickness is only slightly affected by superheat. Comparison of the calculated results for the superheats of 50 and $80^{\circ} \mathrm{C}$ with the measured thickness shows good agreement, although the $\Delta \mathcal{T}$ of the tundish was used in the calculation, instead of $\Delta T$ actually decreasing in the mold; thus the calculated shell thickness is slightly smaller than the measured thickness.

The calculation method taking account of superheat and fluid flow was proved to be reasonable. As was described above, it was made clear that fluid

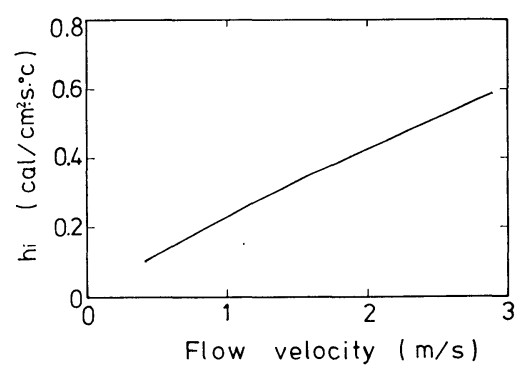

Fig. 6. Liquid/shell heat transfer coefficient $v$ s. flow velocity relationship used for calculation.

Table 4. Data for calculation.

\begin{tabular}{l|c|c||c|c|c}
\hline \multicolumn{3}{c||}{ Belt side } & \multicolumn{3}{c}{ Wheel side } \\
\hline $\begin{array}{c}\text { Flow } \\
\text { velocity } \\
(\mathrm{m} / \mathrm{s})\end{array}$ & $h_{i}^{*}$ & $\begin{array}{c}\text { Time } \\
(\mathrm{s})\end{array}$ & $\begin{array}{c}\text { Flow } \\
\text { velocity } \\
(\mathrm{m} / \mathrm{s})\end{array}$ & $h_{i}^{*}$ & $\begin{array}{c}\text { Time } \\
(\mathrm{s})\end{array}$ \\
\hline 0.6 & 0.17 & $0 \rightarrow 1.7$ & 0.6 & 0.17 & $0 \rightarrow$ \\
1.4 & 0.33 & $1.7 \rightarrow 5.0$ & 0.6 & 0.17 & $\rightarrow$ \\
0.2 & 0.08 & $5.0 \rightarrow 6.4$ & 0.6 & 0.17 & $\rightarrow 6.4$ \\
0.02 & 0.01 & $6.4 \rightarrow$ & 0.02 & 0.01 & $6.4 \rightarrow$ \\
\hline
\end{tabular}

$h_{i}^{*}$ : Heat transfer coefficient between liquid and shell (cal/ $\left.\mathrm{cm}^{2} \cdot \mathrm{s} \cdot{ }^{\circ} \mathrm{C}\right)$ flow and superheat of molten steel affect shell growth. From the calculated results in Fig. 7, although even with the superheat of $90^{\circ} \mathrm{C}$ growth interruption or unfavorable remelting of shell is not likely to occur, higher superheat will result in a difference of solid shell thickness on the transverse section of a cast billet. Therefore as the superheat level, the value of $50^{\circ} \mathrm{C}$, the same as that in conventional continuous casters, has been used.

\section{Effects of Other Casting Conditions on Shell Thickness}

In order to study the effects of casting conditions other than casting temperature on solid shell thickness, casting experiments were carried out during the test run of the commercial caster.

\section{Casting Conditions}

Table 5 shows the casting conditions. Cast metals were $0.2 \% \mathrm{G}$ steel. The experimentally controlled factors were three:

(1) Nozzel stream property:

Under condition $\mathrm{G}$ the nozzle stream was intentionally made turbulent resulting in fluctuation of molten steel level at the meniscus. Under condition D the nozzle stream was made smooth.

(2) Compression or tension casting:

Under condition $\mathrm{G}$ the speed of pinch rollers was

\begin{tabular}{|c|c|c|c|c|c|}
\hline تُّْ & 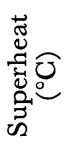 & $\begin{array}{l}\text { Nozzle } \\
\text { stream }\end{array}$ & 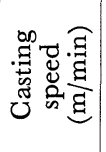 & $\begin{array}{l}\text { Compression } \\
\text { or tension }\end{array}$ & $\begin{array}{c}\text { Guide } \\
\text { roller } \\
\text { configu- } \\
\text { ration } \\
(\mathrm{mm})\end{array}$ \\
\hline G & 58 & Turbulent & 3.1 & Gompression & 130 \\
\hline $\mathrm{D}$ & 50 & Smooth & 3.1 & Tension & 127 \\
\hline
\end{tabular}
slightly lower than the wheel speed in order to com-

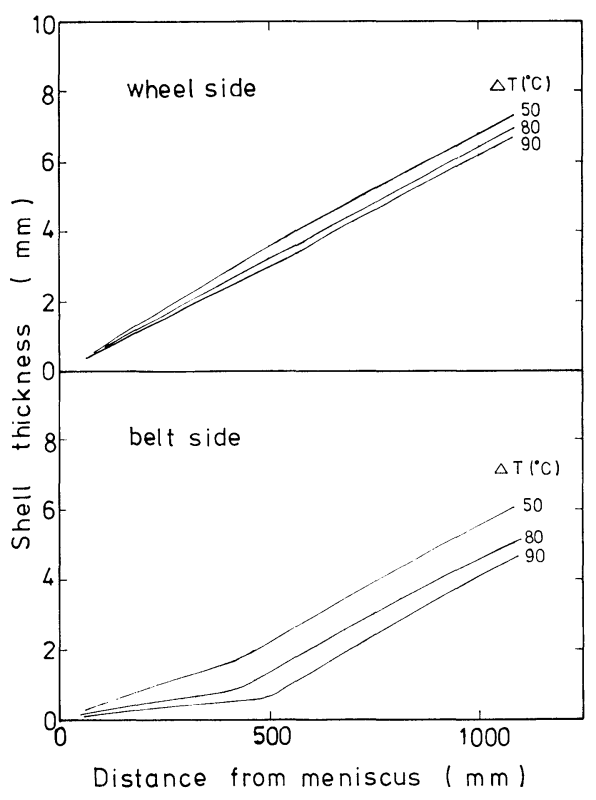

Fig. 7. Effect of superheat $(\Delta T)$ on shell thickness.

Table 5. Casting conditions. 
press a cast billet along the cast direction. Under condition D the pinch roller speed was higher than the wheel speed to pull a cast billet along the cast direction.

(3) Guide roller configuration:

Under condition $\mathrm{G}$ the distance between No. 1 guide roller and the groove bottom of the wheel, as shown in Fig. 2, was set equal to the height of the mold cavity $(130 \mathrm{~mm})$. Under condition $\mathrm{D}$ the distance was set to $127 \mathrm{~mm}$.

\section{Results of Measurement on Shell Thickness}

Figure 8 (b) shows the solid shell thickness vs. distance from the meniscus under condition $\mathrm{C}$. Both along the wheel side and the belt side the shell thickness did not increase gradually and smoothly. On the surfaces of the cast billets some ripple marks were found. The height of the ripple marks $v s$. distance from the meniscus is shown in Fig. 8 (a). The distribution of the height coincided well with the change in the shell thickness. Especially the ripple marks of more than $0.6 \mathrm{~mm}$ height lead to significant decrease in the shell thickness.

Figure 9 (b) shows the shell thickness under condition D. The shell thickness increased gradually along both sides. Figure 9 (a) shows the height of the ripple marks, which was substantially smaller than that under condition C. A cast billet under condition $\mathrm{D}$ showed good quality.

If shell thickness does not increase gradually and smoothly, straightening may not be performed successfully. Thus uniform shell thickness is required for successful straightening. As shown in Figs. 8 and 9, smooth cast surfaces were found necessary for uniform shell thickness.

The solidification rate constant $K$ defined as $Y=$ $K \sqrt{t}$, where $Y$ is shell thickness ( $\mathrm{mm}), t$ is time ( $\mathrm{min}$ ), was about $27 \mathrm{~mm} / \mathrm{min}^{1 / 2}$ under condition $\mathrm{D}$. The rate is somewhat higher than that of a conventional caster. This is due to good contact between a cast billet and the wheel resulted from smooth nozzle stream, tension casting and appropriate guide roller configuration.
Fig. 8.

Shell thickness, height of ripple marks vs. distance from meniscus under condition C.

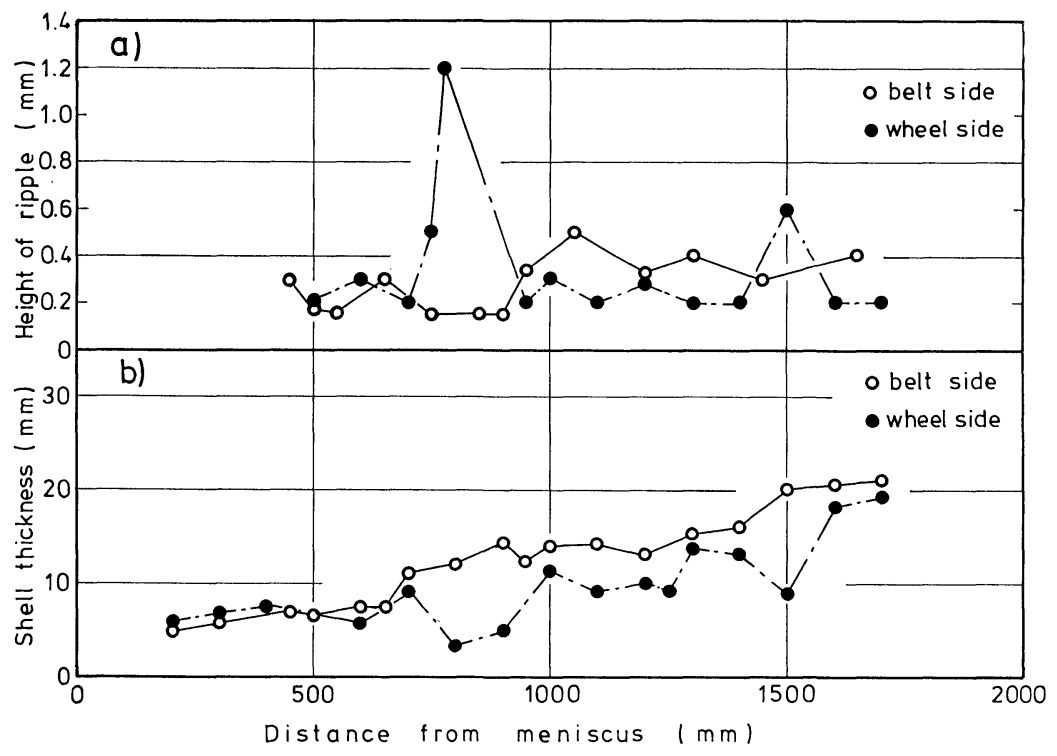

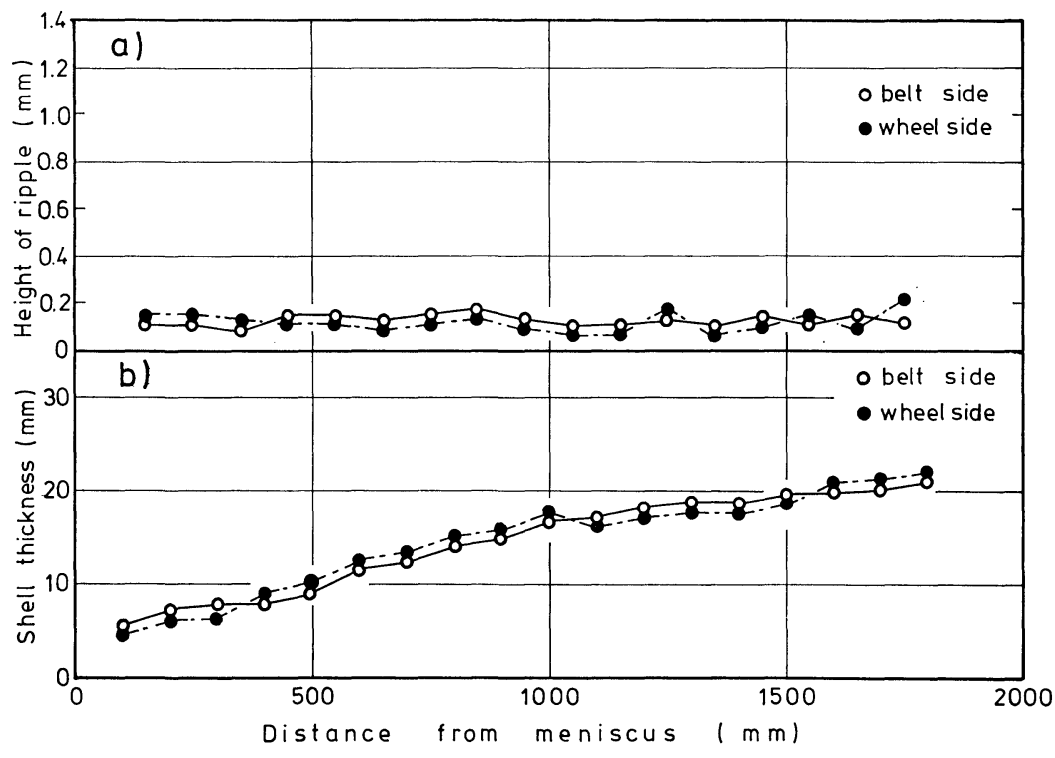

Fig. 9 ,

Shell thickness, height of ripple marks $v s$. distance from meniscus under condition D. 


\section{Heat Transfer of Wheel}

The temperature of the rotating wheel was measured during the test run of the commercial caster in order to study the effects of operating factors on the heat transfer characteristics of the wheel.

\section{Measuring Procedure}

As shown in Fig. 10, in order to measure the wheel temperature during casting, a $1 \mathrm{~mm}$ diameter sheathed chromel/alumel thermocouple was located at the position of $11 \mathrm{~mm}$ below the groove bottom of the wheel through a drilled hole. Table 6 shows the casting conditions. Cast metals were $0.2 \% \mathrm{C}$ steel.

\section{Results and Discussion}

Figure 11 shows the results. While under both conditions the wheel temperature rose sharply after the measured position passed the meniscus and about $12 \mathrm{~s}$ later reached the maximum, there was seen a difference in the falling of temperature. While under condition $\mathrm{E}$ the temperature fell rapidly, the onset of temperature fall was $4 \mathrm{~s}$ longer under condition F. Due to tension casting and pressing of a cast billet to the wheel mold through No. 1 guide roller a cast billet and the wheel mold seem to have been in good contact just before straightening. Condition F resulted in cast billets with good quality.

Therefore, in order to perform uniform tensile deformation on the upper side of a cast billet during straightening, contact between a cast billet and the rotating wheel must be kept good and uniform shell thickness needs to be formed.

The heat flux $q$ of the rotating wheel, calculated from the temperature/time profile in Fig. 11 is expressed in terms of time $t(\mathrm{~s})$ as:

$$
q\left(\mathrm{kcal} / \mathrm{m}^{2} \cdot \mathrm{h}\right)=(2.31-0.257 \sqrt{t}) \times 10^{6}
$$

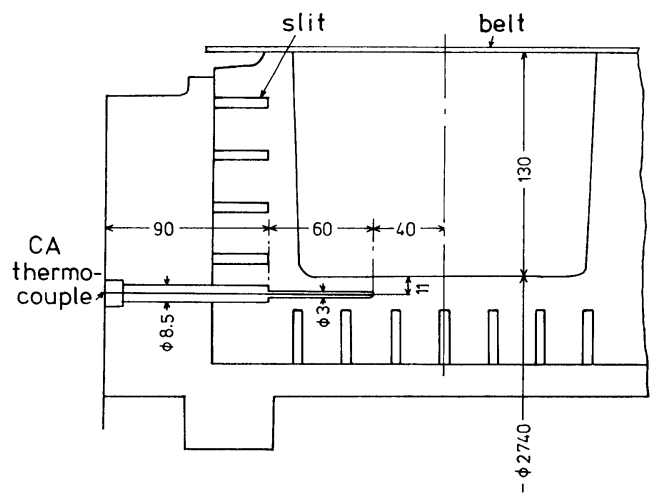

Fig. 10. Location of CA sheathed thermocouple.

Table 6. Gasting conditions.

\begin{tabular}{c|c|c|l|c}
\hline $\begin{array}{c}\text { Condi- } \\
\text { tion }\end{array}$ & $\begin{array}{c}\text { Super- } \\
\text { heat } \\
\left({ }^{\circ} \mathrm{C}\right)\end{array}$ & $\begin{array}{c}\text { Casting } \\
\text { speed } \\
(\mathrm{m} / \mathrm{min})\end{array}$ & $\begin{array}{c}\text { Compression } \\
\text { or tension }\end{array}$ & $\begin{array}{c}\text { Guide } \\
\text { roller } \\
\text { configu- } \\
\text { ration } \\
(\mathrm{mm})\end{array}$ \\
\hline $\mathrm{E}$ & 34 & 3.1 & Compression & 130 \\
$\mathrm{~F}$ & 55 & 3.1 & Tension & 127 \\
\hline
\end{tabular}

The second coefficient is about $10 \%$ smaller than that of an oscillation mold of an average conventional caster. The synchronized wheel mold seems to have better contact with a cast billet than an oscillation mold.

From the casting experiments in Chapters $I I I$ to $V$, the optimum casting and operating conditions were established.

\section{Conclusions}

In the course of development of the synchronized rotary type continuous caster casting experiments with the prototype and commercial machines were carried out in order to study the effects of casting conditions and the operating conditions on the solidification of a cast billet and on the heat transfer of the rotating wheel. The results are summarized in the following.

(1) The solid shell thickness of the belt side was smaller than that of the wheel side when the molten steel largely superheated was poured.

(2) Water modeling test revealed that flow with high velocity went downward along the belt side, while the upward flow with low velocity existed along the wheel side.

(3) The allowable degree of superheating was estimated to be $50{ }^{\circ} \mathrm{C}$ by the casting experiments and computer calculation taking account of fluid flow and superheating.

(4) Good contact between a cast billet and the wheel was obtained by smooth nozzle stream, tension casting where the pinch rollers were driven at a slightly higher rate than the wheel and appropriate guide roller configuration.

(5) The solidification rate constant was $27 \mathrm{~mm} /$ $\min ^{1 / 2}$, which was somewhat larger than that of an average conventional caster.

From these results the optimum conditions were established and the belt wheel type continuous caster was successfully put into practical use.

\section{Acknowledgements}

The authors are grateful to Professor T. Kusakawa, Waseda University, who was the Chairman of High Speed Continuous Casting and Direct Rolling Committee of Mechanical Social Systems Foundation, Dr. R. Nakagawa, Director-General of National Research Institute for Metals, and Professor Y. Kimura, the

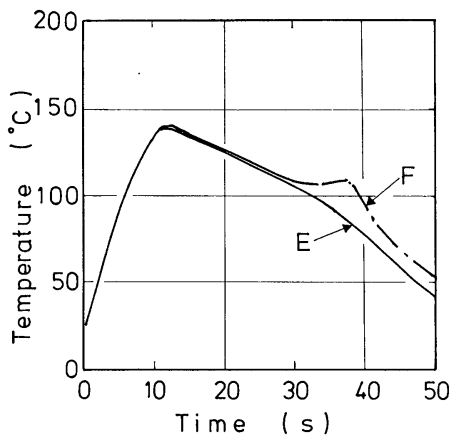

Fig. 11. Temperature vs. time profile of wheel. 
University of Tokyo, who were the members of the Committee. The authors would like to thank Assistant Professor T. Umeda, the University of Tokyo, for discussing the experimental results. Thanks are also expressed to the directors of Daisan Steel Co. for giving the opportunity to carry out the experiments.

\section{REFERENCES}

1) E. Herrman: Handbuch des Stranggiessens, AluminiumVerlag, Düsseldorf, (1958), 1.

2) H. Kodama, E. Niyama, T. Kimura and M. Endo: Proceedings of International Conference on Steel Rolling, I, ISIJ, Tokyo, (1980), 129.

3) B. A. Finlayson: The Method of Weighted Residuals and Variational Principles, Academic Press, New York, (1972), 20.

4) T. Umeda, T. Izawa and Y. Kimura: Proceedings of the 81st Meeting of Japan Inst. Met., Hiroshima, JIM, (1977), 250.

5) JSME Data book: Heat Transfer, ed. and publ. by Japan Soc. Mechanical Engineers, (1975), 73.

6) E. Niyama, H. Kodama, T. Kimura and M. Endo: Iron Steel Eng., 58 (1981), Aug., 38.

7) H. Kodama, E. Niyama, T. Kimura and M. Endo: Iron Age Metalworking International, (1981), No. 4, 16MP17$16 \mathrm{MP} 29$.

\section{Appendix}

Since

$$
\begin{aligned}
& T=f(y, t) \\
& d T=\frac{\partial T}{\partial y} d y+\frac{\partial T}{\partial t} d t=0
\end{aligned}
$$

then

$$
\frac{d y}{d t}=\frac{d Y}{\partial t}=-\frac{\alpha\left(\frac{\partial^{2} T}{\partial y^{2}}\right)_{\boldsymbol{Y}}}{\left(\frac{\partial T}{\partial y}\right)_{\boldsymbol{Y}}}
$$

From Eq. (6),

$$
\begin{aligned}
& \frac{\partial T}{\partial y}=-A_{1}-2 A_{2}(Y-y) \\
& \frac{\partial^{2} T}{\partial y_{2}}=2 A_{2} \ldots \ldots \ldots \ldots \ldots \ldots
\end{aligned}
$$

and

$$
\left(\frac{\partial T}{\partial y}\right)_{Y}=-A_{1}
$$

hence

$$
\frac{d Y}{d t}=\frac{2 \alpha A_{2}}{A_{1}}
$$

Substituting Eqs. (A-4) and (A-5) in Eq. (4) and rearranging

$$
2 m A_{2}+A_{1}^{2}+\theta_{b} A_{1}=0
$$

From Eq. (A-2), for $y=0$,

$$
\frac{\partial T}{\partial y}=-A_{1}-2 A_{2} Y
$$

Since $A_{0}=\mathcal{T}_{s}$ from Eqs. (3) and (6), then substituting Eq. (A-7) in Eq. (2)

$$
\left.K\left(-A_{1}-2 Y A_{2}\right)=h_{c}\left\{T_{s}-T_{0}\right)+Y A_{1}+Y^{2} A_{2}\right\} \ldots(\mathrm{A}-8)
$$

Solving the simultaneous equations (A-6) and (A-8):

$$
A_{1}=\frac{\left(a_{1}-a_{2} \theta_{b}\right)-\sqrt{\left(a_{1}-a_{2} \theta_{b}\right)^{2}+4 a_{2} h_{c}}\left(T_{s}-T_{0}\right)}{2 a_{2}}
$$

Since $\partial T / \partial y>0, A_{1}$ must be negative from Eq. (A-4). Substituting Eqs. (9) and (A-4) in Eq. (4), then

$$
\frac{d Y}{d t}=\frac{1}{\rho L}\left\{-K A_{1}-h_{i}\left(\mathcal{T}_{b}-\mathcal{T}_{s}\right)\right\}
$$

